\title{
Profil Dan Kesintasan Penderita Kanker Kolorektal Di RSUP Dr. M. Djamil Padang
}

\author{
Astuti,NSA ${ }^{1}$, Rafli, $\mathrm{R}^{2}$, Zeffira, L ${ }^{3}$ \\ ${ }^{1}$ Mahasiswa Fakultas Kedokteran Universitas Baiturrahmah, Padang, Indonesia \\ E-mail : nurulseptiarbi@gmail.com \\ 2 Bagian Radiologi Fakultas Kedokteran Universitas Baiturrahmah \\ 3 Bagian Ilmu Penyakit Anak Fakultas Kedokteran Universitas Baiturrahmah
}

\begin{abstract}
Abstrak
Latar Belakang: Kanker kolorektal menempati posisi keempat dengan 694.000 kematian. Terdapat 5,7\% penderita kanker kolorektal dari semua jenias kanker di Indonesia. Angka kejadian penderita kanker kolorektal masih cukup tinggi serta masih sangat terbatasnya data profil dan kesintasan di Sumatera Barat. Tujuan: Penelitian ini bertujuan untuk mengetahui profil dan kesintasan penderita kanker kolorektal di RSUP Dr. M. Djamil Padang. Metode: penelitian dengan menggunakan desain deskriptif melalui pendekatan cross-sectional. Sampel dari penelitian ini diambil dari data rekam medis seluruh pasien kanker kolorektal yang memenuhi kriteria inklusi. Data diambil dengan menggunakan metode "Simple Random Sampling". Hasil penelitian menunjukan bahwa kelompok usia tertinggi adalah kelompok usia 46-55 tahun 38,1\%, jenis kelamin terbanyak laki laki 81\%, keluhan utama dengan konstipasi 33,3\%, stadium B dengan jumlah 47,6\%, operasi penatalaksanaan terbanyak dengan $61,9 \%$, dan kesintasan selama 2 tahun sebanyak 54,5\%. Kesimpulan: Kelompok usia terbanyak didapatkan pada usia 46-55 tahun. Jenis kelamin laki-laki lebih banyak didapatkan dibandingkan perempuan. Keluhan utama yang paling sering muncul adalah konstipasi. Stadium terbanyak pada penelitian ini adalah stadium B2.
\end{abstract}

Katakunci — Profil, Kanker Kolorektal, Kesintasan.

\begin{abstract}
Background: Colorectal cancer is ranked fourth with 694.000 death. As many as $5.7 \%$ of patients with colorectal cancer from all types of cancer in Indonesia. The incidence of colorectal cancer patients is still quite high, and there is still minimal profile and survival data in Sumatera Barat. Objective: This study aims to determine the profile and survival of colorectal cancer patients in Dr. RSUP M. Djamil Padang. Method: this uses descriptive category design through a cross-sectional approach. Samples from this study were taken from medical records of all colorectal cancer patients who met the inclusion criteria. Data retrieval was done by the "Simple Random Sampling" method. Results showed that the highest age group was the age group 46-55 years (38.1\%), the highest sex male (81\%), chief complaint with constipation (33.3\%), stage B with (47.6\%), most management operations with (61.9\%), and survival for 2 years as much as $(54.5 \%$. Conclusion: The largest age group is found at the age of 46-55 years. Male gender is more obtained than female. The main complaint that most often arises is constipation. The largest stage in this study was stage B2.
\end{abstract}

Keywords-Profile, Colorectal Cancer, Survival. 


\section{Pendahuluan}

Kanker merupakan penyebab utama kematian di seluruh dunia, terhitung terdapat 14 juta kasus da 8,2 juta kematian pada tahun 2012. Kanker kolorektal sendiri menempati posisi keempat dengan 694.000 kematian. 1

Hasil survei RISKESDAS, kanker kolorektal ada sebanyak 5,7\% dari semua jenis kanker di Indonesia. 2 Profil Kesehatan Indonesia tahun 2008 menyebutkan bahwa kanker kolorektal menempati urutan ke 9 dari 10 peringkat utama penyakit kanker yang diderita pasien rawat inap di seluruh rumah sakit di Indonesia dengan jumlah kasus sebanyak 1.810. 3 Di RSUP Dr. M. Djamil Padang sendiri tercatat pasien kanker kolorektal pada periode 2002-2007 sebanyak 257 orang. 4

Insiden kanker kolorektal mulai meningkat secara bermakna setelah usia 40 tahun.5 Secara keseluruhan, 90\% kasus baru dan 94\% kematian terjadi pada umur 50 tahun atau lebih. Angka insidensi kanker kolorektak 15 kali lebih tinggi pada umur 50 tahun keatas daripada mereka yang berumur 20-49 tahun.1

Perubahan gaya hidup dan pola makan yang mempengaruhi terjadinya kanker kolorektal. ${ }^{6}$ Kanker kolorektal juga dapat disebabkan karena kebiasaan merokok yang merupakan salah satu risiko terjadinya kanker kolorektal. $^{7}$

Kunci utama dari keberhasilan penanganan kanker kolorektal adalah ditemukannya kasus dalam stadium dini, sehingga terapi dapat dilaksanakan secara kuratif. Namun, sebagian besar pasien datang dalam keadaan lanjut sehingga umur dan harapan hidup rendah walaupun telah diberikan banyak terapi. ${ }^{8}$ Tingkat kelangsungan hidup relatif untuk kanker kolorektal adalah $65 \%$ pada 5 tahun setelah terdiagnosis dan $58 \%$ pada 10 tahun. ${ }^{9}$

Masih tingginya angka kejadian dan sangat terbatasnya data mengenai profil dan kesintasan penderita kanker kolorektal di Indonesia khususnya di daerah Sumatera Barat.

\section{Metode Penelitian}

Penelitian mengenai profil penderita kanker kolorektal di RSUP Dr. M. Djamil Padang pada tahun 2011-2017. Penelitian ini merupakan penelitian deskriptif dengan pendekatan cross-sectional. Pengambilan data dilakukan pada bulan Desember 2018Januari 2019. Hasil penelitian didapatkan dari data rekam medis. Populasi penelitian ini adalah seluruh pasien kanker kolorektal yang didiagnosis di RSUP Dr. M. Djamil Padang pada tahun 2011-2017. Sampel dari penelitian ini diambil dari data rekam medis yang terdiagnosis kanker kolorektal yang memenuhi kriteria inklusi. Pengambilan data dilakukan dengan metode "Simple Random Sampling".

\section{HASIL}

Pada penelitian ini data diambil dari data rekam medis di RSUP Dr. M. Djamil Padang..

\section{A. Karakteristik Dasar Subyek Penelitian}

Karakteristik dasar subyek penelitian dapat dilihat pada Tabel 1.

TABEL 1 DISTRIBUSI FREKUENSI USIA PADA PENDERITA KANKER KOLOREKTAL DI RSUP DR. M. DJAMil PADANG

\begin{tabular}{llll}
\hline \hline Usia & $\mathbf{n}$ & $\mathbf{\%}$ & IK 95\% \\
\hline$<26$ Tahun & 1 & 4,8 & $0,0-14,3$ \\
26-35 Tahun & 2 & 9,5 & $0,0-23,8$ \\
36-45 Tahun & 4 & 19 & $4,8-38,1$ \\
46-55 Tahun & 8 & 38,1 & $19-57,1$ \\
56-65 Tahun & 2 & 9,5 & $0,0-23,8$ \\
$>$ 65 Tahun & 4 & 19 & $4,8-38,1$ \\
\hline Jumlah & 21 & 100 & \\
\hline
\end{tabular}

Tabel 1. menunjukkan rerata umur subyek 
penelitian adalah 41 (17) tahun dan sebagian besar adalah laki-laki $(57,9 \%)$.

TABEL 2 DISTRIBUSI FREKUENSI JENIS KELAMIN PADA PENDERITA KANKER KOLOREKTAL DI RSUP DR. M. DJAMIL PADANG

\begin{tabular}{llll}
\hline \hline Jenis Kelamin & n & \% & IK 95\% \\
\hline Laki-laki & 17 & 81 & $61,9-95,2$ \\
Perempuan & 4 & 19 & $4,8-38,1$ \\
\hline Jumlah & 21 & 100 & \\
\hline
\end{tabular}

Tabel 2 memperlihatkan bahwa kanker kolorektal didominasi oleh jenis kelamin laki-laki sebanyak 17 orang( $81 \%)$.

TABEL 3 DISTRIBUSI FREKUENSI KELUHAN UTAMA PADA PENDERITA KANKER KOLOREKTAL DI RSUP DR. M. DJAMIL PADANG

\begin{tabular}{llll}
\hline \hline Keluhan utama & n & \% & IK 95\% \\
\hline Perubahan pola BAB & 3 & 14,3 & $0,0-33,3$ \\
Hematokezia & 6 & 28,6 & $9,5-47,6$ \\
Konstipasi & 7 & 33,3 & $14,3-52,4$ \\
Diare & 1 & 4,8 & $0,0-14,3$ \\
Anemia & 2 & 9,5 & $0,0-23,8$ \\
Nyeri abdomen & 2 & 9,5 & $0,0-23,8$ \\
\hline Jumlah & 21 & 100 & \\
\hline
\end{tabular}

Tabel 3 memperlihatkan keluhan utama kanker kolorektal terbanyak adalah konstipasi dengan jumlah 7 orang $(33,3 \%)$

TABEL 4 DISTRIBUSI FREKUENSI STADIUM PADA PENDERITA KANKER KOLOREKTAL DI RSUP DR. M. DJAMIL PADANG

\begin{tabular}{llll}
\hline \hline \multicolumn{1}{c}{ Stadium } & \multicolumn{1}{c}{$\mathbf{n}$} & \multicolumn{1}{c}{$\%$} & \multicolumn{1}{c}{ IK 95\% } \\
\hline A & 0 & 0,0 & 0,0 \\
B1 & 5 & 23,8 & $9,5-42,9$ \\
B2 & 10 & 47,6 & $28,6-66,7$ \\
C & 0 & 0,0 & 0,0 \\
D & 6 & 28,6 & $9,5-47,6$ \\
\hline Jumlah & 21 & 100 & \\
\hline
\end{tabular}

Tabel 4 memperlihatkan stadium pada kanker kolorektal terbanyak adalah stadium B2 sebanyak 10 orang $(47,6 \%)$.

TABEL 5 DISTRIBUSI FREKUENSI

PENATALAKSANAAN PADA PENDERITA KANKER KOLOREKTAL DI RSUP DR. M. DJAMIL PADANG

\begin{tabular}{llll}
\hline \multicolumn{1}{c}{ Penatalaksanaan } & n & \multicolumn{1}{c}{$\%$} & \multicolumn{1}{c}{ IK 95\% } \\
\hline Operasi & 13 & 61,9 & $38,1-81$ \\
Operasi+Kemoterapi & 7 & 33,3 & $14,3-57,1$ \\
Operasi+Kemoterapi+ & 1 & 4,8 & $0,14,3$ \\
\hline
\end{tabular}

\begin{tabular}{lll}
\hline Radioterapi & & \\
\hline Jumlah & 21 & 100 \\
\hline
\end{tabular}

Tabel 5 memperlihatkan bahwa penatalaksanaan terbanyak yang dilakukan pada penderita kanker kolorektal adalah operasi dengan jumlah 13 orang $(61,9 \%)$.

TABEL 6 DISTRIBUSI FREKUENSI STADIUM PADA PENDERITA KANKER KOLOREKTAL DI RSUP DR. M. DJAMIL PADANG

\begin{tabular}{llll}
\hline \hline Kesintasan & n & \% & IK 95\% \\
\hline Hidup & 6 & 28,6 & $9,5-52,4$ \\
Lost follow up & 10 & 47,6 & $23,8-66,7$ \\
Meninggal dunia & 5 & 23,8 & $9,5-42,9$ \\
\hline Jumlah & 21 & 00 & \\
\hline
\end{tabular}

Tabel 6 memperlihatkan pasien yang masih hidup dalam 2 tahun sejak di diagnosis adalah 6 dari 11 sampel $(54,5 \%)$. Namun terdapat 10 dari 21 sampel memiliki status lost of follow up.

\section{Pembahasan}

Hasil penelitian di RSUP Dr. M. Djamil Padang menunjukkan bahwa penderita kanker kolorektal paling banyak dengan rentang usia 46-55 tahun. Menurut penelitian yang dilakukan oleh Yogi, dkk kasus kanker kolorektal ditemukan terbanyak pada usia 40-60 tahun, diikuti pada usia $>60$ tahun dan usia $<40$ tahun. $^{10}$ Diagnosis kanker kolorektal progresif meningkat pada usia 40 tahun, meningkat tajam setelah 50 tahun, dan lebih dari $90 \%$ kasus terjadi diatas usia 50 tahun. ${ }^{5}$

Jumlah kasus pada laki-laki lebih tinggi daripada perempuan, yaitu 17 laki-laki (81\%) dan 4 perempuan (19\%). Hasil ini sesuai dengan kepustakaan yang menyebutkan bahwa dari 20 responden yang menderita kanker kolorektal terdapat 14 orang $(70 \%)$ berjenis kelamin laki-laki. ${ }^{11}$

Proporsi penderita kanker kolorektal didapatkan bahwa keluhan utama paling banyak didapatkan dengan keluhan utama 
konstipasi sebanyak 7 orang $(33,3 \%)$. Hasil ini bertolak belakang dengan penelitian lain yang menyebutkan bahwa BAB berdarah dan berlendir merupakan gejala klinis yang paling sering ditemukan sebanyak 25 orang $(9,62 \%) .12$ Buang air besar baik nyata maupun samar menandakan adanya obstruksi parsial oleh neoplasma maligna yang mengalami ulserasi dan mengenai pembuluh darah. ${ }^{13-15}$

Berdasarkan stadium pada penderita kanker kolorektal didapatkan hasil terbanyak dengan stadium B2 yaitu 10 orang $(47,6 \%)$. Penelitian ini sejalan dengan hasil yang diperoleh di Rumah Sakit Immanuel Bandung bahwa penderita kanker kolorektal paling banyak datang dengan stadium B berjumlah 19 orang $(30,1 \%) .16 \mathrm{Hal}$ ini dapat disebabkan karena kanker kolorektal biasanya tidak memberikan gejala awal. Pasien baru datang apabila sudah terjadi gejala pada umumnya seperti obstruksi, perdarahan atau akibat penyebaran sehingga akan terjadi keterlambatan deteksi dini dan penanganan. Lambatnya deteksi dini dan penanganan tersebut dapat disebabkan oleh kurangnya kesadaran dan tingkat pengetahuan pasien untuk datang ke tenaga medis sehingga mengakibatkan terlambatnya diagnosis dan penatalaksanaan. ${ }^{17}$

Berdasarkan penatalaksanaan penderita kanker kolorektal diperoleh hasil paling banyak dengan penatalaksanaan operasi yaitu 19 orang $(61,9 \%)$. Hasil ini didukung dengan penelitian yang dilakukan di RSUP Dr. Moewardi bahwa operasi merupakan penatalaksanaan terbanyak dengan 21 orang $(60 \%){ }^{18}$ Pengobatan paling utama pada kanker kolorektal adalah operasi, dimana jenis operasi yang dilakukan tergantung pada stadium kanker. Tujuam utama tindakan bedah adalah untuk memperlancar saluran cerna, baik bersifat kuratif maupun nonkuratif. $^{19}$

Hasil penelitian dari 21 responden mengenai kesintasan 2 tahun yaitu sebanyak 6 orang $(28,6 \%)$ mampu bertahan hidup, 5 orang $(23,8 \%)$ meninggal dunia, dan 10 orang (47\%) dengan status lost follow up. Proporsi kesintasan dari 11 responden didapatkan 6 orang $(54,5 \%)$ hidup dan 5 orang $(45,4 \%)$ meninggal dunia.

Kanker kolorektal merupakan salah satu kanker yang paling umum terjadi dengan insiden yang diperkirakan akan terus meningkat di tahun-tahun mendatang. Meskipun kemajuan besar dalam pengobatan, angka kematian akibat kanker kolorektal tetap tinggi dan $40-50 \%$ pasien akhirnya meninggal karena penyakit tersebut.19 Tingkat kelangsungan hidup relatif untuk kanker kolorektal adalah $65 \%$ pada 5 tahun setelah terdiagnosis dan $58 \%$ pada 10 tahun.9.

\section{KESIMPUlan Dan SARAN}

Kelompok usia terbanyak didapatkan pada usia 46-55 tahun. Jenis kelamin laki-laki lebih banyak didapatkan dibandingkan perempuan. Keluhan utama yang paling sering muncul adalah konstipasi. Stadium terbanyak pada penelitian ini adalah stadium B2. Operasi merupakan penatalaksanaan yang paling mendominasi pada hasil penelitian ini. Kesintasan penderita kanker kolorektal selama 2 tahun didapatkan sebesar 54,5\%. Terdapat 47,6\% pasien yang tidak bisa dilacak status kesintasannya karena lost of follow up. Dibutuhkan system registrasi kanker dan pencatatan follow up yang baik untuk mendapatkan data Provinsi sumtera barat yang lebih akurat.

\section{Daftar Pustaka}

[1] Izzaty AH. Hubungan antara Faktor Usia Dengan Kejadian Kolorektal Di RSUD Moewardi Surakarta Tahun 2010-2013; Universitas Muhamadiyah Surakarta; 2015.

[2] Dewi, M. Sebaran Kanker di Indonesia, Riset Kesehatan Dasar 2007. Indonesian Journal of Cancer. 2017; 11(1):1-8. 
[3] Wahyuni Syukuriyah Tatuhey, Helfi Nikijuluw, J. M. Karakteristik Kanker Kolorektal di RSUD Dr. M Haulussy Ambon Periode Januari 2012-Juni 2013. Mollucca Medica Jurnal Kedokteran dan Kesehatan. 2014; 4(2):150-57.

[4] Zahari, A. Laporan Kasus Hereditary NonPolyposis Colorectal Cancer(Lynch Syndrome) Pada Wanita Umur 16 Tahun. Majalah Kedokteran Andalas. 2011; 35(2):172-80.

[5] Khosama, Y. Faktor risiko kanker kolorektal. Fakultas Kedokteran Universitas Sam Ratulangi. 2015; 42(11):829-32.

[6] Khosama, Y. et al. Perbandingan, lingkar pinggang, dan rasio pinggang sebagai faktor risiko kanker kolorektal. Jurnal Biomedik. 2016; 8(2):96-101.

[7] Nishihara, R. et al. A prospective study of duration of smoking cessation and colorectal cancer risk by epigenetics-related tumor classification. American Journal of Epidemiology. 2013; 178(1):84-100.

[8] Zahari, A. Deteksi dini, diagnosis dan penatalaksanaan kanker kolon dan rektum. Fakultas Kedokteran Universitas Andalas; 2011.

[9] Alteri R. Colorectal Cancer Facts \& Figure 2017 2019. Atlanta: American Cancer Society; 2017.

[10] Dwipiutra, Yogi, et al. Profil Penderita Kanker Kolorektal di RSUP Sanglah Denpasar Periode 2010-2014. Rumah Sakit Umum Pusat Sanglah Denpasar; 2014.

[11] H. Amnzu, Zuraida R, H. Y. Correlation between Food Intake (Fiber and Fat)and The Occurrence of Colorectal Carcinoma at RSUD Dr. H. Abdul Moeloek Bandar Lampung. Fakultas kedokteran Universitas Lampung; 2013.

[12] Hamdi, A. et al. Profil Karsinoma Kolorektal di LAboratorium Patologi Anatomi Fakultas Kedokteran Universitas Andalas Periode Januari 2009-2011. Jurnal Kesehatan Andalas. 2015; 4(2): 398-403.

[13] Desen W, Zhizhong. Kanker usus besar. Di dalam: Desen W (ed). Buku Ajar Onkologis Klinis. Edisi ke-2. Jakarta: Balai penerbit fakultas kedokteran universitas Indonesia; 2008. 423-41

[14] Acosta J, Alarcon LH, Anaya DH, Ashley SW, Auerbach PS, Azizzadeh A, et al. Townsend: sabiston textbook of surgery.18th ed. United States of America; 2008.

[15] Abdullah, M. 2007. Buku ajar ilmu penyakit dalam. Cetakan kedua. Pusat penerbitan ilmu penyakit dalam fakultas kedokteran indonesia. Jakarta. 373-8.

[16] Winarto, E. P., Ivone, J. \& Saanin, S. N. J. Prevalensi Kanker Kolorektal di Rumah Sakit Immanuel Bandung Periode Januari 2005 Desember 2007. Fakultas Kedokteran
Universitas Kristen Maranatha Bandung. 2009; 8(2):138-45.

[17] Winanda, W. Pola Distribusi Pasien Kanker Kolorektal di Ruang Rawat Inap RSU Dr. Soedarso Pontianak Tahun 2007-2011. Universitas Tanjungpura Pontianak; 2013.

[18] Munawaroh, I. R. Gambaran profil penderita kanker usus besar dan penatalaksanaannya di RSUP Dr. Moewardi; 2012

[19] Kuipers, E. J. dkk. Colorectal cancer. Nat Rev Dis Primers. 2015; 15065. 